\title{
Successful and Efficient Knowledge Management in the Greek Hospitality Industry: Change the Perspective!
}

Belias Dimitrios

Research Fellow, Dept. of Business Administration, TEl of Thessaly, Greece

Rossidis loannis

Administrative Director in $H Q A$, Lecturer at the University of the Aegean, Corresponding Author

Velissariou Efstathios

Professor, Department of Business Administration, TEl of Thessaly, Greece

\section{Amoiradis Christos}

Lecturer, Department of Business Administration, TEl of Thessaly, Greece

Tsiotas Dimitrios

Seasonal Lecturer in Mathematics, Polytechnic School, University of Thessaly, Greece

\section{Sdrolias Labros}

Professor, Department of Business Administration, TEl of Thessaly, Greece

Doi: 10.2478/ajis-2018-0019

\section{Abstract}

In a constantly evolving world, new devices and technologies are incorporating. Organizations should follow the technological changes of the rest of the world if they want to keep up. Standards that were valid few years ago are no longer valid. In this new age knowledge has surpassed other traditional factors, such land, labor and capital. This paper approaches the historical evolution of knowledge, as well as the reasons that have made it an influential factor for organizations wishing to survive, using the tourist industry by way of an example. Furthermore, this paper explores how knowledge management can become a useful tool in the process of leveraging a tourist organization. Knowledge Management is a relatively new concept. Nevertheless, it has become a very popular term, which is increasingly used nowadays. Knowledge management focuses on organizational change under specialized guidance. The paper aims to analyze contemporary literature review in order to enhance the apprehension of how knowledge can become a useful tool not only to overcome crisis but also to contribute to the creation of new ideas and innovations. The paper seems to agree with Mantas (2016)'s view that knowledge management can become a tool to overcome the crisis and also to create innovative ideas which will contribute to the further development of tourism. The research outcome indicates that Organizations will be strongly benefited by such an approach.

Keywords: Knowledge management, tourism, Greece, learning organization 


\section{Introduction}

Tourism is one of the main pillars of the Greek economy, as it employs a significant number of employees, which are a key component of the success of tourism businesses. The most appropriate working environment is the one that combines the satisfaction of staff needs with the satisfaction of the business objective that the decision-making team poses each time. Exploring how to treat a worker as a separate individual and placing him in a working group as an active member with the aim of maximizing his / her best work performance on the one hand and simultaneously satisfying him / her is the ideal combination for striking a balance between his performance at work and positive psychology in his role as a worker.

Hotel business is also a service provider, where the human factor as a productive factor "work" plays a central role and therefore employees have a prominent position between productive resources and can lead them to economic success. This is because the employees are the link of the hotel business with the customer and through their contact with the customer they represent the whole image of the hotel (Cohen \& Olsen, 2015). Therefore, the effective operation of employee incitement and the satisfaction of their individual needs flexible and well-skilled workers to a higher level of performance, both in quantitative and qualitative terms at the same time. The company's strategy should be shaped in such a way that it attaches great importance to attracting the right workforce as well as being empowered to empower its staff by implementing training programs and incitement methods so that staff are able to provide high quality services. A crucial element is the ability of the hotel to take advantage of the knowledge that its employees have developed but also to empower them so to learn and improve themselves (Cooper, 2006). So, the purpose of this paper is to examine the case of how the Greek tourist companies can take advantage of the knowledge which is found within the minds of their personnel; hence to develop knowledge management policies.

This is a literature review. This means that the whole paper will use theories and other material which will derive from a research in published reports and papers. The authors have made a research on online databases and other points where they can gather the material used on this paper. Regarding the expected results, this is a research which relies on secondary sources. Hence, the expected outcome is to produce the related theories and discuss it in detail.

\section{Literature Review}

\subsection{The value of the personnel.}

Effective management is an inherent motivation and the difference it has in relation to other types of incentives is that the empowerment is achieved within from this it is continuous and daily. A manager must cultivate a favorable environment where thought, action, individual behavior will be enhanced. Organizations can contribute to the well-being of employees when: 1. Informing staff about organization and strategies 2. Taking part in the decision making 3. Avoiding mistreatment 4. Informing staff about their performance 5. Strengthening diversity (Tsai et al., 2015; Nikova et al, 2015).

What a company needs is a leadership with emotional intelligence. Managing human resources requires social and emotional ability. A good and effective manager is required to have empathy, i.e. to understand what people feel, to get in their place, to cultivate contact and to coordinate with many different people (Tsai et al., 2015). In addition to the emotional intelligence needed by a manager, he must also be aware of the feeling of "good stress". Good stress refers to the pressure that pushes the person into action.

The leader of a decision-making group knows he can sway the decision he wants and in most cases he only wants a validation of his views. Incitement and performance will only come to the workers when dissent and freedom of opinion are encouraged, and even more so when the views of employees are taken into account when making a decision. One of the most important and critical decisions is to educate the personnel so to make them learn to produce new knowledge and to exploit the existing knowledge. 
Education is a useful technique where many businesses adopt to strengthen employees' skills and knowledge and is one of their most important strategies for attracting new staff and retaining already recruited staff. According to recent research, human resource education strongly contributes to organizational engagement (Hanaysha, 2016).

Employees express the need to be given the opportunity to develop them skills that will allow them to perform better. Continuous improvement is the desire for new data. Both work and learning are of a social nature. People learn better when they are totally committed to what they do and the more they practice doing a job, the better they face the challenges they may be experiencing. Education is indispensable regardless of age because the same opportunities for education and development should be offered to improve their performance and broaden their horizons (Kefis et al, 2014; lun \& Huang, 2007).

\subsection{Knowledge management}

Knowledge management is perhaps the most important activity for a business. Having properly organized the knowledge that she gathers from her daily routines, is able to accomplish the following tasks (Nonaka \& Toyama, 2015),:

- Manage in a uniform way and have valuable organizational information (e.g. workflows, data charts, etc.)

- Avoid wasting resources on tasks that are often repeated and for which they can use preexisting knowledge

- Organize better its resources and time

- Improve and accelerate the training of new employees

- To encode and retain knowledge as its own intellectual property even when its employee leaves

The main problem that one faces in trying to create a business knowledge base is the fragmentation of knowledge in the different departments and the cautiousness of people sharing their knowledge with others. To this end, a system of knowledge organization and management should be incorporated into the day-to-day business of the enterprise in an opaque way, turning the recording of knowledge into a typical activity, which will have to help workers rather than weaken them.

The solutions available to you when designing a new information system are usually two: either to complete existing tools that will each cover a part of the company's needs or to develop from the outset an information system that suits perfectly the needs.

The first option leads very quickly to a solution that does not cover $100 \%$ of the initial needs and therefore requires the company to accept modifications and cuts to its original objectives. The second option requires much more resources, time and money to materialize (Nonaka, \& Toyama,, 2015).

\subsection{Knowledge Management Systems}

Knowledge Management Systems (KM Systems) are systems that allow employees to have direct access to a knowledge base of the organization's knowledge base, information resources and solutions. Through the knowledge management process, experiences, ideas and incidents that can facilitate people or entire organizations are created, recorded, organized, identified and distributed. Many businesses invest in knowledge management systems, which are often part of business strategy, information technology, or human resources management. As shown in Figure 1, the Knowledge Management process is directly related to learning in every form, formal (at an organization or group level) or atypical (personal). 


\section{IT Learning and KM}

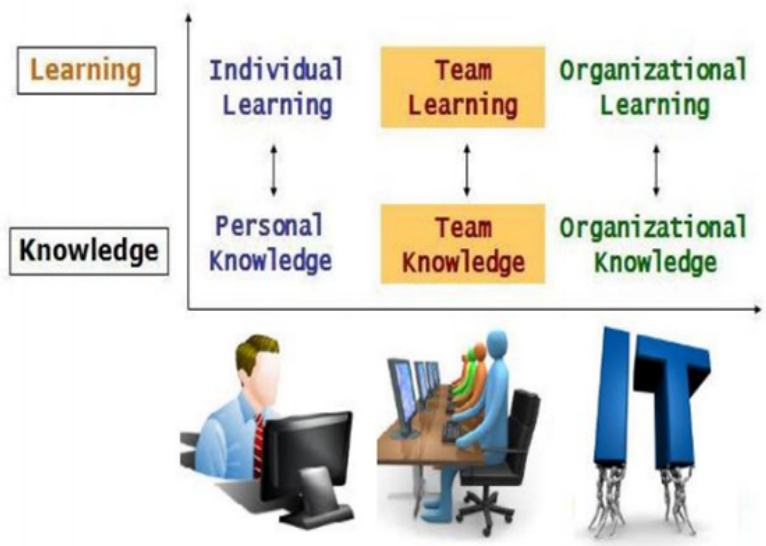

Figure 1. Connecting knowledge to learning Wikipedia Source: http://en.wikipedia.org/wiki/Knowledge_management

The expected benefits for the business can be summarized as follows (Wang et al, 2014):

- Better knowledge of the development and delivery of products and services

- Shorter cycle of new product development

- Better management of innovation

- Exploiting the know-how of people throughout the organization

- Better networking and communication between business executives and external partners

- Evolution of knowledge of employees by gaining experience and ideas about their work

- Resolving insoluble or unresolved problems

- Creating intellectual capital for the business

The process by which knowledge is constantly evolving and expanding is followed by a recurrent flow, as shown in Figure 2, to the creation and externalization of knowledge, to the combination of other existing and relevant knowledge, the reintegration of the knowledge produced and the notification inside the business, and so on.

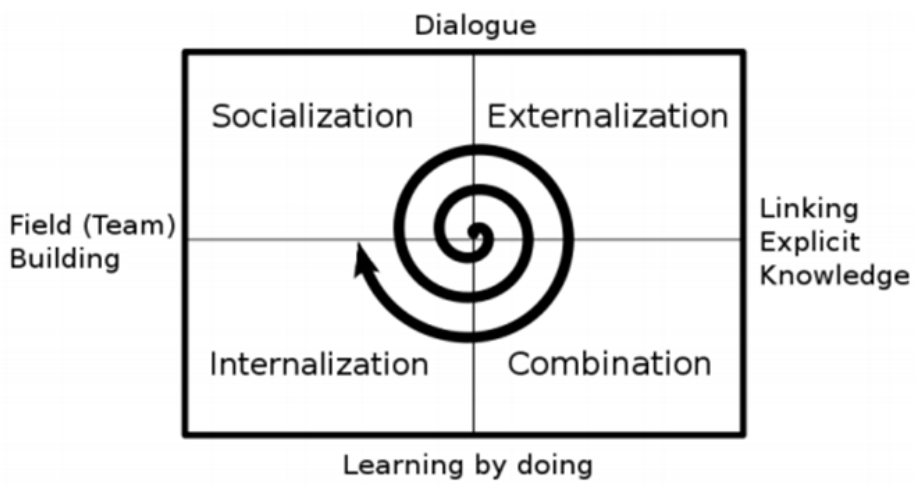

Figure 2: The process of creating and managing knowledge

Source: Nonaka \& Toyama, (2015) 
In order to understand the need for a Knowledge Management system in the business, we quote the following examples.

- An engineer could implement the process of creating a SAP clone system and the problems it may face during the course or this function will facilitate the exchange of technical information at departmental level information technology can lead to faster and more efficient implementation of the process as well as to update it with new information arising from the current procedure

- A technician could restore a cube to an ESSBASE ORACLE HYPERION base.

- A trainee technician could recover a HP-UX system using ignite backup system cartridge

- A help desk user could connect an ERP user to a network printer.

- A development engineer could solve the problem that occurred in one concurrent program at the close of the accounting period which had reappeared last year (Hislop, 2013)

In many cases, knowledge accumulated by an organization becomes part of its day-to-day activities, and from informal or semi-structured knowledge, it becomes a Business Rule. Very often, businesses ask for knowledge management information systems to incorporate these rules into individual processes. In the framework of the work, an attempt was made to support the creation of such rules and to integrate them in the automation of the request handling process. In a very simple approach that demonstrates the capabilities of such systems, depending on the keywords used by a request, the help desk user is proposed for sections that may be able to handle the request

\section{Discussion}

In many cases, knowledge accumulated by an organization becomes part of its day-to-day activities, and from informal or semi-structured knowledge, it becomes a Business Rule. Very often, businesses ask for knowledge management information systems to incorporate these rules into individual processes. In the framework of the work, an attempt was made to support the creation of such rules and to integrate them in the automation of the request handling process. In a very simple approach that demonstrates the capabilities of such systems, depending on the keywords used by a request, the help desk user is proposed for sections that may be able to handle the request (Terry et al, 2013).

Tourism is a service-based industry. This means that the quality of the services provided and the end result depends a lot on the human capital of the tourist company. Knowledge management can contribute into a successful and effective management of the knowledge that the employees have on their disposal (Nieves \& Segarra-Ciprés, 2015). For example, a front-office employee knows well what the weaknesses of the tourist company are while the employee can be the one who will find the solution. The aim of the knowledge management systems is to organize those thoughts and ideas so to turn them into new products and solutions.

According to a research conducted by Velissariou \& Krikeli (2008) in a large number of Hotels in Greece, the majority of the employees in the hotel industry are not highly educated. Especially employees with only Secondary School (Lyceum) certificate or with "Basic (obligatory) education" in 2 star to 5 star hotels, amounts to a total of $62,3 \%$, of the overall personnel number. In 5 stars hotels the personnel educational level is, as expected, higher than in the rest of the Hotels. In both categories, "Post graduate staff" and also "Staff with a University degree", represents the 30,8\% of all personnel, compared to the $19,1 \%$ of higher educated staff in 3 star hotels.

Table 1: Educational level of personnel in Hotels in Greece by category Velissariou Efstathios \& Krikeli Olga (2008)

\begin{tabular}{|c|c|c|c|c|c|c|}
\hline $\begin{array}{c}\text { Educational level of personnel } \\
\text { in Hotels by category }\end{array}$ & $\begin{array}{c}\text { Post } \\
\text { graduate }\end{array}$ & $\begin{array}{c}\text { University } \\
\text { degree }\end{array}$ & $\begin{array}{c}\text { Technical } \\
\text { school }\end{array}$ & $\begin{array}{c}\text { Secondary } \\
\text { School (Lyceum) }\end{array}$ & $\begin{array}{c}\text { Basic } \\
\text { education }\end{array}$ & $\begin{array}{c}\text { Basic + } \\
\text { Lyceum }\end{array}$ \\
\hline $5^{*}$ & $2,33 \%$ & $28,49 \%$ & $26,37 \%$ & $24,95 \%$ & $17,86 \%$ & $42,81 \%$ \\
\hline $4^{*}$ & $1,76 \%$ & $18,86 \%$ & $21,76 \%$ & $33,76 \%$ & $23,87 \%$ & $57,63 \%$ \\
\hline $3^{*}$ & $1,58 \%$ & $17,54 \%$ & $16,08 \%$ & $42,02 \%$ & $22,78 \%$ & $64,80 \%$ \\
\hline $2^{*}$ & $1,17 \%$ & $17,25 \%$ & $12,87 \%$ & $46,49 \%$ & $22,22 \%$ & $68,7 \%$ \\
\hline $5^{*}-2^{*}$ & $1,55 \%$ & $18,80 \%$ & $17,40 \%$ & $39,84 \%$ & $22,42 \%$ & $62,26 \%$ \\
\hline
\end{tabular}


At the same time, Continuing education is applied to the majority of $5^{*}$ hotels, in a percentage of $95,5 \%$. On the contrary in the $4^{*}$ and $3^{*}$ hotels, a high percentage of hotels of about $26 \%$, does not include any program of education, neither participates in programs of education of other institutions. It's quite interesting to mention that the $59,1 \%$ of $5^{*}$ hotels apply programs of education for their new personnel, while in $4^{*}$ hotels the percentage goes up to $32,6 \%$ and in the $3^{*}$ it reaches the $23,3 \%$, while $2 *$ hotels only educate a $7,89 \%$ of new staff. (table 5 below)

Table 2: Continuing training in Hotels in Greece by category Velissariou Efstathios \& Krikeli Olga (2008)

\begin{tabular}{|c|c|c|c|c|}
\hline $\begin{array}{c}\text { Continuing training in } \\
\text { Hotels by category }\end{array}$ & $\begin{array}{c}\text { Internal organized } \\
\text { seminars }\end{array}$ & $\begin{array}{c}\text { External } \\
\text { Seminars }\end{array}$ & $\begin{array}{c}\text { Programs for new } \\
\text { staff }\end{array}$ & $\begin{array}{c}\text { No training } \\
\text { (seminars) }\end{array}$ \\
\hline $5^{*}$ & $77,30 \%$ & $59,10 \%$ & $59,10 \%$ & $4,50 \%$ \\
\hline $4^{*}$ & $44,90 \%$ & $42,86 \%$ & $32,65 \%$ & $26,53 \%$ \\
\hline $3^{*}$ & $30,00 \%$ & $60,00 \%$ & $23,33 \%$ & $25,00 \%$ \\
\hline $2^{*}$ & $13,16 \%$ & $26,32 \%$ & $7,89 \%$ & $63,16 \%$ \\
\hline $5^{*}-2^{*}$ & $32,16 \%$ & $42,53 \%$ & $23,41 \%$ & $37,84 \%$ \\
\hline
\end{tabular}

Mantas (2016) has provided empirical evidence from a number of Greek firms which includes many service-based companies, including tourist companies, which indicated the knowledge management can become very useful in a time of economic turmoil. It can help a company to create new ideas, find solutions and to become a learning-based organization that is ready to provide innovations.

Also, knowledge management can be used on many other types of tourist services. For example, when there is the time to book a package or to create a tourist product, a knowledge management system can store all of the previous packages along with offers, details and prices so to help the tourist manager to come up with an effective offer that will meet the client's demands. For this reason there are many information systems, such as Amadeus, which are used for booking but also they can be used a knowledge management systems which they can help the tourist company and its officers to make their inquiries easier but also to ensure the high quality of their services (Thomas \& Wood, 2014).

It is important to remember that today the competitive advantage comes from the new ideas and the ability to cope with problems. For this reason a knowledge management system will help the tourist companies to capitalize their intellectual capital and to use it as a mean to become more competitive.

\section{Conclusions and Recommendations for Future Research}

Modern business management experts argue that the business knowledge, technology and information available to the company are its most important resources. It is also important for the company to manage them efficiently in order to remain competitive (Nieves \& Haller, 2014). As knowledge, technology and information cannot be copied easily and directly, it is necessary to have information systems that allow the collection, storage, processing and dissemination of knowledge in the various departments of the company.

A knowledge management system can become a useful tool for a tourist company. It is a fact that tourist companies can deal with a great deal of information. Therefore if the company's management has the unique ability to manage this information but also to capitalize it so to turn it into a knowledge that will generate a sustainable competitive advantage. It seems that there has not been much research into this. While Mantas (2006) had identified a set of interesting points and that knowledge management can become a source of competitive advantage, still there is a need to focus a future research into the area of tourist operations. This can be with qualitative research and a case study analysis. The sample can be managers and employees who are working in tourist companies which have developed knowledge management systems. The aim will be to evaluate those systems and see how they are working. 


\section{References}

Cohen, J. F., \& Olsen, K. (2015). Knowledge management capabilities and firm performance: A test of universalistic, contingency and complementarity perspectives. Expert Systems with Applications, 42(3), 1178-1188.

Cooper, C. (2006). Knowledge management and tourism. Annals of tourism research, 33(1), 47-64.

Geisler, E., \& Wickramasinghe, N. (2015). Principles of knowledge management: Theory, practice, and cases. Routledge.

Hanaysha, J., 2016. Examining the Effects of Employee Empowerment, Teamwork, and Employee Training on Organizational Commitment. Procedia - Social and Behavioral Sciences, 229, pp.298-306.

Hislop, D. (2013). Knowledge management in organizations: A critical introduction. Oxford University Press.

http://en.wikipedia.org/wiki/Knowledge_management

Kefis, V., \& Aspridis, G. (2014). Management and development of the human resource of NGOs in Greece : Utopia or reality?, International NGO Journal, 9 (4), (p.p. 43-52).

Mantas, C. (2016) Lost in Translation: Greek-based Enterprises struggle to adopt Knowledge Management and Learning Organisation approaches, PhD Thesis, University of Leicester

Nieves, J., \& Haller, S. (2014). Building dynamic capabilities through knowledge resources. Tourism Management, 40, 224-232.

Nieves, J., \& Segarra-Ciprés, M. (2015). Management innovation in the hotel industry. Tourism Management, 46, 51-58.

Nieves, J., Quintana, A., \& Osorio, J. (2014). Knowledge-based resources and innovation in the hotel industry. International Journal of Hospitality Management, 38, 65-73.

Nikova, D., Aspridis G., Koffas S. (2015). Sociology of labour and HRM : An interdisciplinary approach, Proceedings in 5th International Conference on Humanities and Social Sciences, (p.p. $66-73$ )

Nonaka, I., \& Toyama, R. (2015). The Knowledge-creating theory revisited: knowledge creation as a synthesizing process. In The essentials of knowledge management (pp. 95-110). Palgrave Macmillan UK.

Terry Kim, T., Lee, G., Paek, S., \& Lee, S. (2013). Social capital, knowledge sharing and organizational performance: what structural relationship do they have in hotels?. International Journal of Contemporary Hospitality Management, 25(5), 683-704.

Thomas, R., \& Wood, E. (2014). Innovation in tourism: Re-conceptualising and measuring the absorptive capacity of the hotel sector. Tourism Management, 45, 39-48.

Tsai, C.Y. et al., 2015. Work environment and atmosphere: The role of organizational support in the creativity performance of tourism and hospitality organizations. International Journal of Hospitality Management, 46, pp.26-35.

Velissariou Efstathios \& Krikeli Olga (2008).The Human factor as criteria of quality in hotels. Measurements in the Greek Hotel sector. 1st International Conference on Tourism and Hospitality Management. Organized by Tourism Research Institute of DRATTE. 13-15 June 2008 Athens.

Wang, S., Noe, R. A., \& Wang, Z. M. (2014). Motivating knowledge sharing in knowledge management systems: A quasi-field experiment. Journal of Management, 40(4), 978-1009. 